\title{
La renovación peronista en cuestión: una aproximación a la experiencia del peronismo durante la década del '80
}

\author{
The renewal peronism in question: an approach to the experience of \\ peronism during the ' $80 \mathrm{~s}$
}

\author{
Germán Basso ${ }^{1}$
}

\section{RESUMEN}

Este trabajo recorre la experiencia sufrida por el peronismo durante la década del '80, prestando especial atención a la fracción conocida con el nombre de Renovación Peronista. Los renovadores, que en un comienzo se definieron en contraposición a los dirigentes ortodoxos que controlaban el $\mathrm{PJ}$, irán paulatinamente ganado espacios dentro del partido hasta lograr acceder a su control formal a comienzos de 1988. Una vez desplazados los ortodoxos de las posiciones de poder dentro del PJ , se desatará en el interior del grupo renovador un enfrentamiento entre sus dos máximos representantes, Antonio Cafiero y Carlos Menem, produciendo una severa modificación en la composición y el sentido de la Renovación. Comprender los procesos que desencadenaron el origen y el desarrollo posterior de la Renovación es el objetivo primario de este artículo, así como también explorar su identidad dentro del contexto político argentino.

PALABRAS ClaVE: Renovación Peronista. KeyWORDS: Renewal Peronism. Perón.

Peronismo. Cafiero. Historia política Cafiero. Political history of Argentina. argentina.

\section{ABSTRACT}

This article surveys the experience suffered by Peronism during the '80s, with special attention to the fraction known as the Renewal Peronism. The renewals, which at first were defined in opposition to the orthodox leaders who controlled the PJ, will gradually won spaces within the party to gain access to formal control in early 1988. Once displaced the orthodox from positions of power within the PJ, was unleashed a confrontation inside the renewal fraction between its two top representatives, Antonio Cafiero and Carlos Menem, causing a severe change in the composition and direction of the Renewal Peronism. To understand the processes that triggered the origin and subsequent growth of the Renewal Peronism is the primary objective of this article, as well as explore their identity within the political context of Argentina.

\section{Las Elecciones de 1983}

El final del Proceso de Reorganización Nacional en 1983 fue el inicio de un nuevo ciclo en la política argentina. Conjuntamente con la instauración de la democracia como sistema de gobierno, se generó un nuevo consenso en torno a la necesidad de preservar el estado de derecho respetando los Derechos Humanos que la

\footnotetext{
1 Licenciado en Historia en la Universidad Nacional de La Plata (UNLP), Argentina. Colaborador de las Carpetas Docentes de Historia del Siglo XX (http:// www.carpetashistoria.fahce.unlp.edu.ar/). Realizó una maestría en Periodismo en la Universidad de San Andrés. En su tesina de licenciatura abordó a la revista Unidos y a la renovación peronista durante la década de 1980.
} 
dictadura había violado sistemáticamente. Este "nuevo tiempo político" (VOMARO, 2006) marcó un quiebre no sólo respecto a los años oscuros del Proceso, sino también respecto a los agitados años '70, donde la violencia era aceptada como un instrumento de la política por gran parte de sus actores.

Una de las figuras que logra un notable protagonismo en este nuevo panorama es Alfonsín, quien en poco tiempo conseguirá erigirse como el líder de un radicalismo renovado. Con un discurso alejado de la moderación que había mantenido el anterior presidente de la Unión Cívica Radical (UCR), Ricardo Balbín, en tiempos de la Multipartidaria, Alfonsín enfatizó durante la campaña presidencial el antagonismo entre autoritarismo y democracia, reivindicando sin ambigüedades las instituciones republicanas. Las innovaciones en el discurso que pone en práctica el alfonsinismo le permitirán aggiornar la imagen de la UCR, posicionándose por delante del peronismo y de gran parte de la ciudadanía argentina en los reclamos de justicia y castigo a las Fuerzas Armadas por las violaciones a los derechos humanos cometidas durante el Proceso. Como destaca Aboy Carlés (2004), el discurso enunciado por Alfonsín formaba una frontera en dos sentidos: respecto al pasado reciente, en el cual reinaba el autoritarismo, y respecto a los actores que encarnaban ese pasado. Si bien la opinión pública reconocía en las Fuerzas Armadas al principal actor del Proceso, cierta ala del peronismo aparecía comprometida en él, en particular aquella parte de la dirigencia sindical que ahora detentaba el control del PJ . Esta operación de asimilar a peronistas y militares se vería expresada en la denuncia que el propio Alfonsín hará sobre un pacto militar-sindical en marzo de 1983, poniendo de manifiesto la cercanía existente entre estos actores. Si bien Alfonsín nunca pudo aportar pruebas fehacientes sobre este supuesto pacto, la situación que atravesaba el peronismo durante la campaña electoral posibilitó que esta denuncia tuviera amplia credibilidad dentro del electorado.

Los casi ocho años de dictadura no habían transcurrido sin afectar el multipolar movimiento peronista. Tanto la extrema derecha, encarnada en la Alianza Anticomunista Argentina (Triple A), como la izquierda peronista de Montoneros y la J uventud Peronista, habían dejado de existir. La burguesía nacional nucleada en torno a J osé Gelbard se había prácticamente extinguido por las políticas económicas liberales de Alfredo Martínez de Hoz y Roberto Alemann. Solamente dos sectores lograron mantener su poder dentro del partido: la dirigencia sindical, y los caudillos en las distintas provincias y en las localidades del Gran Buenos Aires. Pero sólo el sindicalismo peronista poseía la capacidad política y económica para controlar el PJ .

Durante el ocaso de la dictadura, los sindicatos habían obtenido la normalización de los gremios y la devolución de las obras sociales. Gracias al retorno de 
esta fuente de financiamiento, el sindicalismo, controlado por dirigentes peronistas, pasó a convertirse en el único sector dentro del PJ con recursos para volcar en la carrera política. En los principales bastiones electorales, donde los sindicatos solían ser fuertes, éstos se encargaron de los gastos en publicidad, de proveer los locales como sedes de campaña y de desarrollar actividades para la recaudación de fondos. Al desplegar sus organizaciones en la vida política del PJ, los sindicatos lograron hegemonizar la conducción del partido, tanto a nivel local como provincial, obteniendo el apoyo de importantes dirigentes políticos dentro del peronismo. Esta situación quedará reflejada en el Congreso Nacional J usticialista celebrado en Buenos Aires entre el 3 y el 6 de septiembre de 1983, en el cual Lorenzo Miguel, Secretario General de la UOM y de las 62 Organizaciones Peronistas, será designado Vicepresidente del PJ . Este cargo pasó a ser el de mayor importancia, debido a que quien había sido designada como Presidenta del partido, María Estela Martínez de Perón, se encontraba viviendo en España, y no tenía intención de intervenir en la vida interna del justicialismo. Asimismo, los dirigentes sindicales obtuvieron una cuota importante de las candidaturas a diputados y senadores, especialmente en la Capital Federal, y en las provincias de Buenos Aires, Santa Fey Córdoba.

El control del partido por los sindicalistas generó tensiones con otros sectores internos del peronismo, especialmente con algunos dirigentes políticos que no encontraron lugar dentro del nuevo armado del justicialismo. Un caso sintomático fue el protagonizado por Cafiero, cuyas aspiraciones a participar dentro de la fórmula presidencial quedaron truncas cuando el Congreso J usticialista de septiembre del '83 oficializó las candidaturas Ítalo Luder y Deolindo Bittel como presidente y vicepresidente respectivamente. Una vez desplazado, Cafiero intentó alcanzar la candidatura a la gobernación de Buenos Aires, pero resultó marginado nuevamente, esta vez por Herminio Iglesias. Esta situación abrió claramente una brecha entre quienes controlaban el partido y quienes apoyaban a Cafiero -en ese entonces una agrupación denominada $\mathrm{MUSO}^{2-}$, que comenzarían a plantearse seriamente la necesidad de impulsar una renovación dentro del partido, tanto en sus dirigentes como en sus prácticas internas.

El primer gran desafío al cual se enfrentó este peronismo con presencia hegemónica del sindicalismo fueron las elecciones de diciembre de 1983. El triunfo de Alfonsín marcó el fin de una de las premisas más fuertes del peronismo: el de representar a la mayoría. El 51\% de los votos obtenidos por la UCR, frente al $40 \%$ del

2 El Movimiento Unidad, Solidaridad y Organización (MUSO) fue fundado en septiembre de 1982, entre otros, por Antonio Cafiero, Deolindo Bittel, Miguel Unamuno y la Comisión de los 25. 
PJ , inaugura una nueva etapa en la política argentina, donde, siguiendo a Vommaro, la elección "ya no sería un espacio de confirmación de una supremacía anterior, sino el momento de constitución de una mayoría" (VOMARO, 2006). Quienes dirigían el PJ fracasaron en esta construcción, y sus causas pueden encontrarse en la forma en que condujeron su campaña electoral. El visible poder dentro del partido de un sindicalismo desprestigiado a los ojos de la opinión pública, los enfrentamientos entre ciertos sectores de izquierda y de derecha en los actos partidarios, y la intención demostrada por el candidato a la presidencia, Ítalo Luder, de buscar la reconciliación con el menoscabado régimen militar, fueron algunos de los rasgos de la campaña que más perjudicaron el desempeño electoral del PJ. Un hecho que condensa este peronismo del cual el electorado decidió alejarse se dio durante el cierre de campaña de Herminio Iglesias, cuando un cajón fúnebre con el escudo de la UCR fue incendiado por los allí presentes. Esta imagen del cajón en llamas representó para quienes vieron las imágenes por televisión o en los diarios, una clara expresión de retorno a un peronismo donde la violencia era moneda de cambio y las virtudes democráticas tenían escaso valor.

\section{El Rearmado del Peronismo en los Primeros Años de Alfonsín: el Rol de Opositor}

$\mathrm{Si}$ bien la derrota electoral del peronismo fue un duro revés para quienes dirigían el partido, su conducción no se vio amenazada inmediatamente. El sindicalismo mantendría su poder dentro del PJ, resultando inclusive fortalecido debido al despliegue inicial del gobierno de Alfonsín, especialmente con la denominada "Ley Mucci".

Esta ley apuntaba a revertir la hegemónica presencia del peronismo dentro del sindicalismo argentino -en cuya labor la dictadura había fracasado- dando un nuevo orden jurídico a unas organizaciones obreras donde pervivían reglas de juego poco democráticas según la opinión generalizada.

El Proceso, que en un principio había decretado la suspensión de toda actividad sindical, promulgó en noviembre de 1979 una nueva ley de asociaciones gremiales en la cual el poder de los sindicatos era fuertemente recortado gracias, entre otras cuestiones, a un aumento del control del Ministro Trabajo, a la separación de las obras sociales de los sindicatos, y a la prohibición de conformar confederaciones u organismo de tercer grado. Asimismo, los sindicatos debían reformar sus estatutos en sintonía con la nueva disposición, lo que demoró el procedimiento de normalización a 
tal punto que en marzo de 1982 un nuevo decreto (n. 549) permitía al Ministro de Trabajo designar delegados normalizadotes de los sindicatos, conformando las denominadas "comisiones transitorias". En 1983 otro decreto dispondrá que estas comisiones deberán elevar a la autoridad administrativa el programa de normalización del sindicato, a fin de regularizar definitivamente su situación. La J unta Militar, desprestigiada luego de la derrota en Malvinas, apresuró las elecciones de autoridades sindicales ante la necesidad de enfrentar una creciente oposición al gobierno. En estos comicios, cuestionados a los ojos de la opinión pública por supuestas irregularidades, gran parte de las antiguas cúpulas peronistas resultaron electas $\mathrm{y}$, gracias a la devolución de las obras sociales, contaron con recursos para volcar en los gastos de campaña de las elecciones presidenciales. Ya con Alfonsín en el poder, estas mismas cúpulas se perfilaban como uno de los principales opositores al flamante gobierno radical.

Con la firme intención de democratizar una amplia gama de espacios de poder y corporaciones, Alfonsín envió al Congreso el proyecto de Ley de Reordenamiento Sindical y su Régimen Electoral el 16 de diciembre de 1983, seis días después de haber asumido como Presidente. Esta ley, popularmente conocida como “Ley Mucci” por haber sido redactada por el entonces ministro de Ministro de Trabajo, Antonio Mucci, apuntaba a "imponer serias restricciones a los mecanismos que tradicionalmente habían facilitado la permanencia de las viejas cúpulas gremiales" (GUIDO; DOMENICONI, 1983, p. 428). Su punto central consistía en alcanzar una representación sindical fuertemente orientada "de abajo hacia arriba", eligiendo primero a los delegados de base para luego ir componiendo la estructura ascendente, evitando los sistemas electivos establecidos en los estatutos sindicales, que tendían a fortalecer la continuidad de las direcciones y a obstaculizar la competencia interna. En este sentido la ley también buscaba profundizar la fiscalización de las elecciones sindicales, que pasaba a estar sometida a la autoridad de la J usticia Nacional Electoral, y facultaba al Ministro de Trabajo para designar a un "administrador" y a veedores judiciales independientes del proceso electivo. Además establecía un sistema de representación que incluía una mayoría y una minoría en las organizaciones gremiales, y se impedía la posibilidad de que el candidato alcanzara los tres mandatos consecutivos, siendo necesario un período de reincorporación al trabajo de al menos tres años para ser electo nuevamente.

La "Ley Mucci" se mostraba amenazante para un peronismo que venía de ser duramente derrotado en las elecciones, y cuyo rol como oposición al alfonsinismo parecía ser una incógnita para propios y extraños. No sólo podía resultar perjudicial 
para la fuerte presencia del peronismo dentro de los sindicatos, sino que era potencialmente un elemento de discusión y conflicto al interior del mismo PJ .

$\mathrm{Si}$ la intención del gobierno era dividir y debilitar al peronismo mediante la "Ley Mucci", las consecuencias no podrían haber sido más negativas. Como destaca Luis Alberto Romero, ante este desafío "se unificaron todas las corrientes del peronismo, gremial y político" (ROMERO, 2001, p. 252), logrando rechazar el 15 de marzo de 1984 la ley en la Cámara de Senadores, donde el PJ contaba con el bloque más amplio, por el mínimo margen de un voto. Tan sólo un mes después, el desgastado Antonio Mucci renunciará a su cargo para que ocupe su lugar Juan Manuel Casella, quien al poco tiempo de asumir cambiará la estrategia confrontativa del anterior ministro por una de carácter concertador, estableciendo la devolución de los fondos de las obras sociales a los gremios y acordando una normalización inicial de las conducciones sindicales para luego pasar a los niveles inferiores. El peronismo logrará así posponer sus diferencias internas para ejercer un exitoso rol de opositor que permitirá conservar la conducción del partido, al menos de forma circunstancial, a quienes la poseían desde la apertura democrática.

Superada esta primera prueba, el sindicalismo peronista, y especialmente la CGT, ${ }^{3}$ pasó a enfrentarse a practicamente todas las iniciativas del oficialismo. El 3 de septiembre de 1984 la Confederación General del Trabajo realizará el primer paro general desde el retorno a la democracia, en rechazo a la política socioeconómica del gobierno en general, y a su política salarial en particular. Si bien el paro tuvo un acatamiento parcial, cercano al 50\%, sirvió para mostrar que la oposición a la gestión de Alfonsín no era impopular. En esta oposición la CGT no se encontraba sola, y no tardó mucho tiempo para que algunos de los sectores más descontentos con el primer semestre del nuevo gobierno comenzaran a acercar sus posiciones. En ese mismo mes de septiembre la Unión Industrial Argentina (UIA), la Sociedad Rural Argentina (SRA), la Confederación Intercooperativa Agropecuaria Limitada (CONINAGRO), la Cámara de Comercio (CAC), la Coordinadora de Actividades Mercantiles y Empresarias (CAME), la Cámara Argentina de la Construcción, y otras entidades empresarias, junto a la CGT elaboraron un documento en el cual se criticaba la orientación económica del gobierno. Hacia comienzos de 1985 estas coincidencias entre grupos empresarios y sindicales se materializará en la conformación del autodenominado Grupo de los 11,

3 Con el retorno a la democracia, y especialmente frente a la embestida oficialista con la "Ley Mucci", las CTG Azopardo y CGT República Argentina se unieron en lo que se donominó CGT Unificada (CGTU). Las 62 organizaciones tuvieron escasa representación en el secretariado de la CGTU que se componía de cuatro secretarios generales. Uno de ellos, Saúl Ubaldini, se destacó por su labor de oposición al gobierno y pasó a ser el titular de la central obrera luego de su normalización electoral en 1986. 
que logrará presentar una serie de propuestas al gobierno como alternativa al plan económico oficial una semana antes de que renuncie el Ministro de Economía Bernardo Grinspun en medio de una crisis hiperinflacionaria a mediados de febrero de 1985.

Las otras dos cuestiones destacadas a las cuales se opuso el justicialismo en estos primeros años de gobierno radical fueron la firma del tratado con Chile por el canal de Beagle, y la política de Alfonsín frente a los militares acusados de violar los derechos humanos durante la última dictadura. Respecto al problema de límites con Chile, un conflicto de larga data y que se había agudizado durante el Proceso, el J usticialismo se opuso enérgicamente a la salida propuesta por Alfonsín de aceptar el veredicto de la mediación papal, desoída por los anteriores gobiernos militares. Para resolver el problema, el gobierno decidió llamar en noviembre de 1984 a un plebiscito no vinculante que reveló a un abrumador $82 \%$ de los votantes a favor de aprobar la solución propuesta por el Papa, desnudando la escasa aceptación social que tenía la oposición peronista a la firma del tratado. En cuanto a la investigación y el enjuiciamiento a los militares comprometidos con los crímenes del Proceso, el justicialismo coincidió con las críticas realizadas por la Iglesia sobre la creación de la CONADEP y sobre la forma de proceder en los juicios. La coincidencia entre el PJ y la Iglesia se irá profundizando a medida que su mutuo enfrentamiento al oficialismo los haga converger en estos temas y en cuestiones como los proyectos de ley sobre la herencia de los hijos extramatrimoniales y sobre el divorcio, ambos impulsados por el alfonsinismo.

Como argumenta Levitsky, el lugar ocupado por el justicialismo como opositor a las políticas más progresistas del gobierno de Alfonsín, llevó al peronismo a distanciarse aún más de los votantes de clase media e independientes (LEVITSKY, 2005, p. 142). Debido a los cambios en la sociedad argentina durante los "70 y comienzos de los '80, este sector resultaba cada vez más importante a la hora de definir las elecciones. Las políticas económicas de la última dictadura militar pronunciaron una tendencia que ya se expresaba en la Argentina en particular y en el capitalismo en general, de retracción de la clase obrera, y de fragmentación y heterogeneización de los sectores populares. Estos cambios repercutieron negativamente en la base electoral del peronismo, que sufrió una merma notable en sus resultados electorales durante las elecciones de 1983 y 1985, en las cuales mantuvo una plataforma tradicional estatista y populista cuyo eje era el movimiento obrero organizado. La estrategia política del PJ , focalizada hacia la clase obrera peronista y dirigida en gran medida por los propios sindicalistas, no cambió de rumbo pese a los fracasos electorales de los primeros años del retorno a la democracia. Este cambio provino de la mano de un grupo de dirigentes 
con escaso lugar dentro de las estructuras formales del partido y que se darán el nombre de Renovadores.

\section{El Primer intento de Renovación Dentro del PJ}

Las diferencias políticas al interior del partido peronista se mantuvieron latentes durante un tiempo luego de la derrota en las elecciones presidenciales, pero finalmente afloraron hacia fines de 1984. El 9 de diciembre, en vistas a un nuevo congreso partidario, se crea el Frente de Renovación Peronista, compuesto por el MUSO, Convocatoria Peronista -liderada por Carlos Grosso-, el Frente de la Unidad Peronista -de Eduardo Vaca-, la Comisión de los 25 y los ex CGT Azopardo. Seis días después, el 15 de diciembre, se celebra el primer congreso del PJ desde el retorno de la democracia en el Teatro Odeón de Buenos Aires. Con un clima previo marcado por el enfrentamiento verbal, el congreso era esperado por un amplio espectro de peronistas “disidentes" para buscar modificar la conducción partidaria. En ese entonces, entre los disconformes se encontraba el Frente Renovador, cuyas figuras sobresalientes eran Cafiero y Grosso; la llamada liga de gobernadores, liderada por el gobernador de Santiago del Estero Carlos Juárez y donde se destacaban figuras como Vicente Saadi (Gobernador de Catamarca), Raúl Bercovich Rodriguez (candidato a gobernador en Córdoba) y Carlos Menem (Gobernador de La Rioja); el sector de peronistas bonaerenses enfrentados a Herminio Iglesias, donde se destacaba el intendente de Lomas de Zamora, Eduardo Duhalde; y otros dirigentes aislados pero de cierto renombre tales como Oraldo Britos o Deolindo Bittel.

Durante el congreso de Odeón, la conducción reaccionó a las críticas cerrando filas en su interior y buscando la intimidación a los opositores. Intentó esquivar las discusiones planteadas por los congresales en disconformidad, amenazándolos con frases violentas hacia quienes no apoyaran las propuestas del herminismo, llegando a utilizar la agresión física contra Carlos Menem cuando se disponía a abandonar el recinto. En medio de un clima cada vez más tensionado, la conducción del partido buscó nombrar gente de su propia fuerza para las nuevas autoridades partidarias, generando el retiro del teatro de 347 congresales sobre un total de 656. Sin el quórum necesario, fue elegida igualmente la nueva conducción: como Vicepresidente 1 o del PJ a J osé María Vernet, un gobernador de Santa Fe estrechamente vinculado a la UOM, y a Lorenzo Miguel como Vicepresidente $2^{\underline{o}}$-el cargo de Presidente seguiría en manos de la ausente María Estela Martínez de Perón. El sindicalismo ouminista mantenía así su hegemonía sobre los cargos más importantes del Partido. Esta actitud opera como catalizador para los opositores, que si bien logran evitar que Vernet llegue a la $\mathfrak{o}$ 
Vicepresidencia, no podrán establecer una fuerza capaz de desplazar de la conducción al oficialismo.

Estas actitudes inflexibles y agresivas de lo que pasó a llamarse la ortodoxia partidaria o los mariscales de la derrota -Lorenzo Miguel, Herminio Iglesias y los gobernadores o políticos que los apoyaban- fueron repudiadas por gran parte de los dirigentes peronistas, entre quieres se destacaban los renovadores. El clima de descontento generalizado con los sucesos del Teatro Odeón se tradujo en la convocatoria a un nuevo congreso partidario de carácter extraordinario para el 2 de febrero de 1985 en la ciudad de Río Hondo, Santiago del Estero. Prueba del respaldo conseguido por este congreso fue su amplia convocatoria: de los 685 congresales habilitados, 382 acudieron a Río Hondo.

Las resoluciones que se tomaron en la ciudad santiagueña buscaron minar el poder que los ortodoxos tenían dentro del partido, pero sin llegar a una ruptura definitiva. Si bien se mantuvo a Isabel Perón como la Presidenta del partido, se eligieron nuevas autoridades partidarias, entre quienes estaban Oraldo Britos como vicepresidente primero; Roberto García, dirigente sindical del grupo de los 25, como vicepresidente segundo y J osé Manuel de la Sota, referente de la Renovación en Córdoba, como Secretario General. También se modificó el sistema de elección de autoridades partidarias, las que pasaron a ser elegidas por el voto directo de los afiliados en cada distrito provincial, ocupando cada distrito cuatro delegados del Consejo Superior. Este punto era considerado vital por gran parte de los renovadores, al favorecer un vínculo más directo entre dirigentes y bases. Por último, se decidió la intervención del PJ de la provincia de Buenos Aires, y se designó a Luis Salim, un senador santiagueño, para dirigir la normalización. Se buscaba convocar a unas elecciones internas que renovaran las autoridades partidarias y pusieran fin a los enfrentamientos por el control del justicialismo bonaerense, en manos de Herminio Iglesias.

Respecto a la relación entre el sector político y el sindical, el Congreso de Río Hondo logró obtener el apoyo de dos sectores importantes dentro del sindicalismo como lo eran el grupo de los 25 y la Comisión Nacional del Trabajo (CNT). El grupo de los 25, el segundo agrupamiento sindical en importancia dentro del peronismo después de las 62 organizaciones, era un grupo heterogéneo de dirigentes que buscaban una renovación dentro del sindicalismo peronista, tanto en sus métodos como en sus posiciones frente a la sociedad y al Estado. Su principal enemigo era el uominismo miguelista, hegemónico dentro de las 62 organizaciones, y su aliado natural pasó a ser el sector renovador en el plano partidario. Tanto los renovadores como el grupo de los 
25 rechazaban el control del partido ejercido por la rama sindical y compartían la idea de que los candidatos a los cargos partidarios debían ser elegidos por los afiliados. Este último punto buscaba oponerse al denominado tercio sindical reivindicado por las 62 organizaciones, según el cual la rama sindical del peronismo tenía el derecho de nominar a la tercera parte de los candidatos a cargos partidarios. Los miembros de la CNT, en cuyas filas se destacaban dirigentes como J orge Triaca del gremio de los plásticos, se unieron a los renovadores persiguiendo un objetivo más coyuntural: minar la posición hegemónica de las 62 organizaciones dentro del sindicalismo peronista.

El apoyo de los 25 al Congreso de Río Hondo promovió el nombramiento de uno de sus máximos referentes, Roberto García, como vicepresidente del partido, y de Roberto Navarro como secretario de seguridad social, mientras que de la CNT fueron nombrados Delfor Giménez como secretario gremial y Alberto Guibaudo como secretario de acción social. Por el lado de las 62 organizaciones, si bien su falta de normalización conforme a la ley de reordenamiento sindical fue el motivo explícito por el cual no se las sumó a la dirección del consejo surgido en Río Hondo, quedaba claro que la presencia hegemónica del ouminismo miguelista no facilitaría su integración una vez normalizada. Se generó entonces una situación de doble comando dentro del justicialismo, con una conducción ortodoxa que buscaba impugnar judicialmente la validez legal del congreso renovador, y una nueva conducción surgida de Río Hondo.

Pese al éxito del denominado Congreso Renovador, la unión de los distintos sectores que confluyeron en Río Hondo comenzó a revelarse frágil, y rápidamente las posiciones que buscaban la conciliación dentro del peronismo pasaron a tomar fuerza. Una serie de elementos fueron aislando a dirigentes como Cafiero, Britos, De la Sota y García, que buscaban mantener la confrontación contra la ortodoxia, al tiempo que ganaban terreno quienes perseguían la unidad del PJ (Saadi, J ulio Romero y Triaca, entre otros). Uno de los factores que pueden explicar este cambio es la gran heterogeneidad de ideas e intenciones reunidas en Santiago del Estero. La cohesión alcanzada para oponerse a la ortodoxia comenzó a resquebrajarse a la hora de ensamblar un proyecto común, como bien lo resume Norberto Ivancich: “...existían casi tantos grados de renovación e intenciones de democratización como gobernadores o jefes provinciales hay" (IVANCICH, [200-]).

A su vez, varias de las decisiones tomadas en Río Hondo, y vividas como triunfos por parte de los renovadores, comenzaron a caer en el vacío, en parte gracias a la incapacidad de los renovadores, pero también debido a los reflejos de la ortodoxia. Dos claros ejemplos en este sentido fueron la intervención a la provincia de Bs. As. y el apoyo de los agrupamientos sindicales - el grupo de los 25 y la CNT- a la conducción 
liderada por Oraldo Britos. Salim, quién había sido nombrado interventor con el expreso objetivo de convocar a elecciones internas en la provincia en un plazo no mayor a 150 días, rápidamente cambió su perfil y se presentó como mediador entre las facciones en pugna. Las negociaciones que mantuvo con Herminio Iglesias fueron estirando cualquier tipo de resolución sobre las autoridades partidarias en la provincia bonaerense, que continuarían por un años más en manos del herminismo. En cuanto al apoyo del sindicalismo a la dirección de Río Hondo, en abril de 1985, la CNT se integra a las 62 organizaciones ya normalizadas, dejando aislado al grupo de los 25 y suspendiendo toda posibilidad de crear un sostenido apoyo sindical a la fuerza renovadora que se encuentre en condiciones de disputarle la hegemonía en este rubro a la dirigencia ortodoxa.

Estos elementos, sumados a la predisposición mostrada por figuras como Vernet y Lorenzo Miguel de acercar posiciones para evitar la división del partido, y a la necesidad del peronismo de mostrarse fuerte para enfrentar las elecciones legislativas de octubre, derivaron en la convocatoria a un nuevo congreso celebrado el 6 de julio en Santa Rosa, provincia de La Pampa. El nombre de congreso de la unidad, como se lo conoció en aquel entonces, no reflejaba lo que realmente sucedió en la ciudad pampeana, donde la ortodoxia partidaria logró retomar el control del partido, sumando a sus filas a figuras como Vicente Saadi, padre del entonces gobernador de Catamarca y nombrado vicepresidente primero del PJ ; J orge Triaca, dirigente sindical que había liderado la conciliadora CGT Azopardo, como vicepresidente segundo; Alberto Rodríguez Saá, hermano del gobernador de San Luis que hasta entonces se había mantenido al margen de la disputa por el control partidario, como vicepresidente tercero; y Luis Salim como secretario político. También fue elegido Herminio Iglesias como secretario general mientras que al frente de la presidencia del partido continuó Isabel Perón. Los renovadores quedaron aislados e inclusive sus principales referentes abandonarán la provincia antes de que se reúna el congreso. Nombrados Herminio Iglesias y el ex interventor de la provincia de Buenos Aires como parte del nuevo consejo partidario, la intervención se da por finalizada, y las elecciones internas fijadas para fines de agosto quedan anuladas.

La consecuencia más importante del Congreso de Santa Rosa es el desprendimiento del PJ por parte del los renovadores de cara a las elecciones legislativas de noviembre. La conducción surgida en Santa Rosa se presentó bajo el nombre Frente J usticialista de Liberación (FREJ ULI), mientras que los renovadores se presentaron como Frente Renovador Justicia, Democracia y Participación (FREJ UDEPA) en la provincia de Buenos Aires y en los demás distritos donde habían 
accedido a la conducción partidaria vía elecciones internas como era el caso de Capital Federal. Por último, como Partido Justicialista se denominaron gran parte de los gobernadores peronistas que no se integraron al FREJ ULI.

El gran ganador de la elección fue la UCR, que mantuvo su caudal electoral obteniendo un 43\% de los votos para diputados nacionales, y obteniendo 63 de las 127 bancas para diputados nacionales disponibles. Si bien este triunfo parecía confirmar el liderazgo del alfonsinismo, no logró alcanzar la ansiada mayoría parlamentaria, y el peronismo en su conjunto mantendría su poder en la Cámara Baja. A nivel nacional, El FREJ ULI obtuvo el 16\% de los votos (21 bancas), mientras que el Partido J usticialista consiguió poco menos del 8\% del electorado (15 bancas). Los renovadores nucleados en el FREJ UDEPA con Cafiero como primer candidato a diputado nacional por Buenos Aires lograron obtener cerca de un millón y medio de votos (26\% del electorado provincial) lo que los colocó como el partido escolta de la UCR (41\%) en la provincia y les permitió acceder a 11 bancas de diputados. En este mismo distrito, el FREJ ULI comandado por Herminio Iglesias, obtuvo sólo medio millón de votos, un tercio de los votos renovadores y consiguió apenas 3 bancas. Este resultado marcará, en gran medida, el comienzo de la curva descendente de la carrera política de Iglesias, quien al poco tiempo será marginado de la Secretaría General del Consejo Nacional J usticialista.

En la Capital Federal, donde los renovadores habían ganado la interna partidaria en agosto, el sector ligado a la ortodoxia -y comandado por quien había sido el representante de las 62 organizaciones en la interna, J ulián Licastro- decide romper con el PJ y se presenta como Frente de Liberación, obteniendo cerca de 16.000 votos. El PJ renovador de Capital Federal con Carlos Grosso como primer candidato a diputado logra conseguir casi 500.000 votos, accediendo a 4 de las 13 bancas disponibles.

Más allá de los triunfos de la Renovación sobre la ortodoxia en Buenos Aires y en Capital Federal, las elecciones de octubre mostraron a ambos sectores de la interna peronista lo necesario que resultaba integrar al bando opuesto bajo el propio liderazgo si se quería derrotar al radicalismo en las elecciones de 1987, donde se votarían la Renovación de los diputados nacionales y de las gobernaciones provinciales. La tensión resultante entre los intentos por sumar a los rivales intrapartidarios pero sin resignar espacios de poder que experimentarán tanto los renovadores como la conducción del partido, explica en gran medida las idas y vueltas constantes que se sucedieron durante 1986 y 1987. En el plano político extrapartidario, la Renovación comenzaba a asumir el rol de representación del peronismo pese a los intentos iniciales de Alfonsín que 
buscaban establecer a los ortodoxos como interlocutores válidos, previendo una dura competencia electoral con los renovadores.

El triunfo alcanzado por los renovadores también mostraba de forma incipiente la posibilidad que tenían los dirigentes políticos de emanciparse del financiamiento sindical, vital durante la campaña de 1983. Ahora la rama política del justicialismo podía acceder a importantes recursos estatales mediante los cargos ejecutivos -gobernaciones, intendencias- y legislativos -como senadores, diputados, concejales- que comenzaron a ocupar a partir de 1983. Esta transformación, estudiada en profundidad por Steven Levitsky, posibilitaba una mecánica en la cual los “..punteros locales, que antes se dirigían a los sindicatos en busca de recursos, se volvían ahora hacia los funcionarios del PJ y creaban con éstos alianzas llamadas 'agrupaciones', cuya base principal era el patronazgo' (LEVITSKY, 2005, p. 150). En la tesis de Levitsky, el acceso a los recursos estatales no es el único factor que permite a la dirigencia cambiar la base sindical por una red de relaciones de tipo clientelar, sino fundamentalmente la alta flexibilidad de un partido que desde sus orígenes mantuvo como característica distintiva una escasa rutinización de sus normas y procedimientos. La continua contracción de la clase obrera sumada a una dirigencia sindical públicamente cuestionada, a la posibilidad de acceso a recursos estatales por parte de los políticos del partido y a una débil incorporación de normas que establezcan reglas en la relación de los sindicatos con el partido, posibilitaron una rápida transformación dentro del PJ, convirtiéndolo en un partido con una importante red clientelista. A la postre, estos cambios permitirán la implementación de políticas neoliberales del menemismo en un partido tradicionalmente estatista e intervencionista. Las elecciones de 1985, tímidamente, comenzaron desandar este sendero, aunque todavía en ese entonces resultaba lejana la posibilidad de conformar una fuerza de alcance nacional capaz de disputar el predominio del alfonsinismo. En esa construcción comenzarán los renovadores a volcar sus esfuerzos una vez probada su capacidad electoral frente a los mariscales de la derrota.

\section{La Consolidación de la Renovación y el Origen de sus Internas}

El 21 de diciembre de 1985 en Parque Norte los renovadores nombraron una conducción referencial tripartita compuesta por Antonio Cafiero, Carlos Grosso y Carlos Menem. En esta misma reunión hicieron público el documento fundacional de lo que hasta entonces era una corriente política dentro del justicialismo, titulado "La Renovación Peronista. Un proyecto y una voluntad para transformar la Argentina”. 
Este documento es testigo de un cambio de objetivos dentro del grupo renovador. El desafío central ya no estará puesto dentro del partido, sino fuera de él, en la figura del entonces presidente Raúl Alfonsín. El 1 de diciembre de ese mismo año, Alfonsín había pronunciado ante el plenario de la UCR uno de los discursos más memorables de su gestión, conocido como el discurso de "Parque Norte". Allí el entonces presidente llamaba a una convergencia democrática que, como destaca Aboy Carlés, buscaba dos tipos de acuerdos, no del todo diferenciados en el propio discurso. Por un lado, un "pacto democrático" que fijara las reglas de juego dentro de la institucionalidad propia de la democracia (ABOY CARLÉS, 2004, p. 46-47). Por el otro, un "proyecto de país" sustentado en tres pilares: democracia participativa, ética de la solidaridad y modernización. Emilio de Ipola, partícipe en el armado conceptual del discurso, denomina pacto de garantías y pacto de transformación a estos dos planos del discurso de Parque Norte, y acuerda con Aboy Carlés al destacar lo fusionados que se encontraban ambas dimensiones en Parque Norte. Esta confusión, según de Ipola, respondía a una premisa tácita que circulaba en el entorno presidencial, según la cual “el gobierno debía poner en marcha indisolublemente la transformación y tener éxitos claros en ella, para lograr su anhelada convergencia programática y así dar realidad al pacto de garantías" (DE IPOLA, 2004, p. 56).

El documento fundacional de la Renovación, dado a conocer el 21 de diciembre, se presentaba como una clara respuesta frente a las posiciones esbozadas por Alfonsín en Parque Norte. En él se rescata la democracia, pero se busca dotarla de nuevos contenidos que, según los renovadores, se encontraban ausentes en el discurso del presidente. Carlos Altamirano, al analizar el documento, destaca la contraposición entre democracia liberal o formal y democracia real o social, y apunta que el mensaje central del mismo consistía en que “La transformación [...] no podía ser liderada por un partido liberal y sin voluntad de lucha, como la UCR, sino por el peronismo, que contaba con credenciales históricas para la empresa" (ALTAMIRANO, 2004, p. 67). Leyendo el texto en la clave propuesta por Aboy Carlés y de Ipola, los renovadores aceptaban el pacto de garantías pero no así el de transformación que el alfonsinismo proponía.

En los primeros meses de 1986 se profundizó la consolidación de la Renovación. Se sumaron a la conducción tripartita del espacio renovador, en calidad de secretarios, los diputados J osé Luis Manzano (Mendoza), José Manuel de la Sota (Córdoba) y Orlado Britos (San Luis), y el secretario General de la Comisión de los 25, Roberto García. El 3 de marzo la conducción renovadora realizó una reunión cumbre con la conducción del PJ -representada por Leónidas Saadi, Jorge Triaca y Alberto 
Rodríguez Saá- donde se acordó la normalización por el voto directo de los afiliados de los distritos intervenidos de Buenos Aires, Córdoba, Jujuy y Río Negro, y la implementación de un sistema de representación que contemple a las minorías. Era la apertura de un nuevo espacio de negociación entre los dos polos políticos del peronismo en el cual la Renovación parecía, de a poco, imponer sus propias reglas.

En el marco de este proceso de ordenamiento, la Renovación realizará un congreso en Parque Norte el 22 y 23 de marzo de 1986, que poseerá un doble perfil. Por un lado, este congreso marcará la consolidación de la Renovación, su delimitación en torno a una serie de dirigentes, y la aceptación de esta facción por parte de la conducción ortodoxa. Con ella comenzará a negociar las distintas soluciones para los distritos en condición irregular, ya sea por falta de elecciones internas o por encontrarse intervenidos. Por el otro lado, el Congreso de Parque Norte comienza a mostrar las primeras discrepancias dentro de la Renovación. Estos agrietamientos se irán profundizando con el correr del tiempo y girarán alrededor de dos problemas fundamentales: qué relación deben sostener los renovadores con la ortodoxia partidaria y quién será el candidato a presidente dentro del grupo renovador. Paulatinamente, la bipolaridad ortodoxos-renovadores que se había cristalizado durante 1985 fue reorganizándose en una nueva rivalidad cuyos polos estaban representados por Cafiero y su círculo renovador más cercano -Carlos Grosso, Manuel De la Sota y J osé Luis Manzano- por un lado, y Menem, quién logrará sumar a buena parte de los exortodoxos, por el otro. Un sector de la ortodoxia peronista, especialmente la representada por Lorenzo Miguel, se mantuvo expectante ante esta nueva división del justicialismo sin tomar partido hasta los últimos días de la interna. El año 1986 significó el comienzo de este reacomodamiento.

De forma incipiente, las diferencias entre los dos líderes de la Renovación pudieron apreciarse públicamente durante el primer acto de esta fuerza política en Plaza Once, Capital Federal, el 23 de mayo de 1986. Allí oficiaron de oradores los tres líderes renovadores. Groso y Cafiero enunciaron discursos acordes a lo que ya era una posición habitual, criticando tanto al gobierno como a la ortodoxia del PJ . Menem, en cambio, ensayó un giro fuerte con su alocución en el cierre del acto. Las críticas que Menem asestó al oficialismo en su discurso buscaban “...romper su noviazgo con Alfonsín”, (CERRUTI, 1993, p. 211) ya que el entonces gobernador de la Rioja era uno de los peronistas que más cerca del presidente se había mostrado durante su gobierno. También viró su discurso cuando se refirió a la ortodoxia del partido. En este punto Menem recalcó la necesidad de unir al peronismo como meta principal, marcando una clara diferencia con sus compañeros dentro de la Renovación, que sólo accederían a un 
acuerdo si se establecía aceptando "un necesario recambio de concepción, de dirigentes y de metodologías" (IVANCICH, [200-]) por parte del peronismo ortodoxo.

Durante ese mismo mes, Menem comenzó a hacer pública su voluntad de ser candidato a Presidente para 1989, y empezó a conformar una agrupación propia a nivel nacional que se denominó Federalismo y Liberación, Línea Nacional Rojo Punzó, con la que dio inicio a la construcción de su estructura política de cara a las elecciones presidenciales. Con este mismo fin organizó para el 4, 5 y 6 de julio un "Encuentro Nacional de Renovadores Peronistas para Menem Presidente" en Cosquín, donde hizo los primeros acercamientos con figuras cercanas al herminismo como Luis Barrionuevo, un dirigente sindical del rubro gastronómico que había ocupado el tercer lugar en la lista de diputados que encabezó Herminio Iglesias en las elecciones de 1985. Menem también fue acercándose a la ortodoxia que, pese a encontrarse en plena fase descendente, convocó a un nuevo congreso partidario en San Miguel de Tucumán para los días 3 y 4 de noviembre. Pese a la ausencia de los renovadores cercanos al cafierismo -sólo Grosso concurrió pero se retiró temprano-, Menem se presentó al encuentro y avaló a la nueva conducción, consiguiendo del congreso una reforma que juzgaba vital para acceder a la candidatura a la Presidencia de la Nación: se modificó la carta orgánica del partido definiendo la elección directa y por distrito único para la elección de la fórmula presidencial en 1988.

Para terminar de perfilar este viraje Menem decidió competir contra las listas renovadoras en las internas partidarias de Santa Fe, Buenos Aires y Entre Ríos, ya sea mediante el desembarco de su propia línea interna Federalismo y Liberación o bien apoyando a los opositores de la Renovación. En Santa Fe, donde los comicios internos se realizaron el 19 de octubre, Menem avaló la lista encabezada por Vernet, otrora ortodoxo, frente a la de Raúl Carignano, que contaba con el apoyo de Cafiero y Grosso. El triunfo de Vernet fue un espaldarazo para Menem y terminó con las aspiraciones de Ítalo Luder -quién fue candidato a senador en la lista de Carignano- de acceder a una nueva candidatura presidencial.

En el caso de la provincia de Buenos Aires, Menem decidió presentarse a las internas del 16 de noviembre con su propia lista, Federalismo y Liberación. Si bien afirmaba apoyar la candidatura de Cafiero para la gobernación en las elecciones del año próximo, sus afirmaciones también marcaban su distanciamiento de la Renovación y su formulación de un nuevo proyecto político. En este sentido es sintomática su declaración ante un periodista del diario Clarín el 16 de noviembre de 1986, el mismo día en que se elegían los congresales que determinarían las autoridades partidarias bonaerenses: "[...] he dicho hasta el cansancio que está superado el proceso de la 
ortodoxia y el período de la renovación; no quiero ser referente de ninguno de los dos sino que pretendo serlo del justicialismo a secas" (Clarín, 16/11/ 1986). Los resultados de las internas justicialistas en Buenos Aires dieron un amplio triunfo a la Renovación cafierista, que obtuvo un 64,2\% de los votos y logró colocar 28 miembros en el consejo provisional justicialista. El menemismo, aliado con buena parte de los opositores a cafiero dentro de la provincia, también realizó una muy buena elección consiguiendo un $27,3 \%$ del electorado y ubicando cuatro consejeros partidarios, especialmente si se tiene en cuenta su reciente ingreso en Buenos Aires. El restante 8,5\% de los votos corresponden a distintos candidatos independientes. El sector liderado por Herminio Iglesias, que impugnaba la legalidad de la elección, no se presentó a la misma.

Córdoba fue el último espacio de disputas dentro del peronismo en 1986. En las elecciones convocadas para el 15 de diciembre Menem y los renovadores nuevamente se encontraron apoyando listas enfrentadas. Se elegían convencionales constituyentes para reformar la constitución cordobesa, fundamentalmente para permitir la reelección del gobernador radical Eduardo Angeloz, y el peronismo se presentó con dos listas separadas: el Frente Renovador encabezado por J osé Manuel de la Sota por un lado, y la ortodoxia liderada por Alberto Serú García, y apoyada por Menem, por el otro. Los renovadores obtuvieron un claro triunfo que luego ratificarían en las internas partidarias celebradas en abril de 1987. Allí De la Sota se enfrentó al ortodoxo Bercovich Rodríguez y obtuvo un triunfo categórico con el 80\% de los votos a su favor. Luego de esa elección la ortodoxia cordobesa se desarmará.

\section{Las Elecciones de 1987}

Hasta mediados de 1987, el peronismo vivía las elecciones, en muchos casos, como elecciones internas. En gran medida porque buena parte de las elecciones eran de carácter interno, pero también porque cuando se enfrentaba al radicalismo, éste último solía ganarlas con facilidad frente a un peronismo cuyas facciones luchaban por los segundos puestos. Una de las variables que explicaba esta situación, como hemos visto antes, radicaba en un debilitado y dividido peronismo; la otra residía en un oficialismo con alta imagen positiva. El éxito en la estabilización de la economía logrado por el Plan Austral entre 1985 y 1986, junto a los avances en los juicios a los militares responsables del Terrorismo de Estado, resultaron claves para explicar el alto nivel de consenso experimentado por el gobierno hacia mediados de los ` 80 y su consolidación electoral durante esos años. Un hecho anecdótico, pero que revela este panorama, es el llamado a convocar, entre 1984 y 1985, un Tercer Movimiento Histórico por parte del radicalismo, en el cual se incluiría a los sectores más progresistas de un peronismo que 
se encontraba en crisis. Inclusive algunos peronistas, como Raúl Matera y Ángel Robledo, se sumaron a este proyecto y llegaron a declarar la muerte del peronismo.

Este panorama comenzó a cambiar entre fines de 1986 y mediados de 1987, con el deterioro de la situación económica y los cambios en la política militar. El aumento de la inflación, que duplicó la del año anterior alcanzando un 175\% anual en 1987, junto a un aumento del déficit público y una drástica disminución de las reservas del Banco central, repercutieron negativamente en una economía que nuevamente comenzaba a perder el rumbo. Los índices sociales tales como el desempleo, subempleo, pobreza e indigencia se vieron afectados de forma negativa por este contexto, alcanzando en 1987 sus peores cifras desde el retorno a la democracia. El otro frente que también opacó el desempeño del gobierno fue la cuestión militar. En este terreno, luego del juicio y condena a las juntas militares vividas en el año 1985, y que tan de cerca fueron seguidos por la opinión pública, el gobierno se vio obligado a impulsar las primeras “Leyes de Perdón” para evitar tanto la extensión de los juicios a buena parte de los subordinados dentro de las fuerzas militares como una disputa con esos sectores que terminará en un enfrentamiento armado. Particularmente con la sanción de la Ley de Obediencia Debida en junio de 1987 se profundizará el clima de derrota en las políticas del gobierno en torno al juicio y castigo a los responsables de la represión ilegal durante la última dictadura, debilitando uno de los flancos más fuertes del oficialismo hasta ese entonces.

El peronismo, por el contrario, llegaba a las elecciones de septiembre de 1987 habiendo superado buena parte de los problemas que afectaron su desempeño electoral en años anteriores. El avance de la Renovación, especialmente en determinados distritos como Buenos Aires, Mendoza y Córdoba, volvió a unir al peronismo alrededor de un candidato, permitiéndole encarar las elecciones con serias perspectivas de triunfo. Las líneas del cafierismo y el menemismo, que se habían perfilado como potenciales rivales en su mutua aspiración presidencial durante el año anterior, pondrán a un lado su competencia para buscar consolidar fuerzas en pos de derrotar al radicalismo en los distintos distritos.

En las elecciones del 6 de septiembre, la Renovación pudo comprobar sus posibilidades electorales, ya no sobre la ortodoxia partidaria, sino sobre el oficialismo. El peronismo en su conjunto logró obtener un $41 \%$ de los votos en la elección de diputados nacionales frente a un 37\% de la UCR, alcanzando casi la mitad de las bancas en disputa -60 sobre un total de 127-. En el plano de las gobernaciones el justicialismo fue realmente contundente en sus triunfos sobre el radicalismo: apenas dos provincias fueron retenidas por esta última fuerza, mientras que el PJ triunfó en 17 sobre un total 
de 22. Córdoba fue una de las dos provincias donde la UCR logró alcanzar la gobernación y representó un revés para la Renovación Peronista ya que uno de sus representantes más destacados, Manuel de la Sota, perdió por unos 5 puntos porcentuales contra el radical Eduardo Angeloz.

El triunfo más resonante para la Renovación fue el de la provincia de Buenos Aires, un distrito que compone nada menos que un tercio de electorado nacional. Allí Cafiero logró consagrarse gobernador obteniendo unos 2,8 millones de votos, equivalentes al 46,5\% de los votos emitidos. Esta victoria de la Renovación cafierista, posicionaba al nuevo gobernador bonaerense como el peronista con el cargo más trascendente dada la importancia del distrito, desplazando de ese lugar a otros gobernadores peronistas, entre ellos al reelecto gobernador por La Rioja, Carlos Menem. Si bien éste último había apoyado la candidatura de Cafiero, una vez conocidos los datos de la elección la competencia dentro de la interna justicialista se recrudeció, gracias a las aspiraciones de Menem a ser candidato presidencial y al nuevo lugar que ocupará Cafiero dentro del partido. Los carteles que aparecieron pegados en la ciudad porteña al día siguiente a la elección permitían apreciar esta tensión: "Ahora más que nunca unidos y con Menem".

\section{La carrera Hacia las Internas: del esplendor al Fin de la Renovación}

Tras la elección de septiembre la Renovación encabezada por Cafiero pasó a liderar de hecho el aparato partidario del peronismo. En las formas, esta situación pasó a oficializarse el 8 de enero de 1988 durante una reunión de gobernadores en Mar del Plata, al confirmarse las nuevas autoridades partidarias. La Lista Unidad, que asumirá la conducción del PJ el 9 de enero, estaba capitaneada por Cafiero como presidente y Menem como Vicepresidente. Las vicepresidencias $1^{\circ}$ y $2^{\circ}$, ocupadas por Vernet y Roberto García respectivamente, exponían la solución encontrada al problema de la representación sindical: se incluyó en cargos casi idénticos a un representante de las 62 Organizaciones y a otro de grupo de los “25”. La Secretaría General y la Secretaría Política estaban ocupadas por otros dos representantes de la Renovación como lo eran Grosso y De la Sota.

Según apunta Gabriela Cerruti, esa reunión de gobernadores también sirvió para que tanto Cafiero como Menem dieran por tierra con los últimos intentos por conformar un acuerdo de unidad para las elecciones presidenciales capaz de evitar un enfrentamiento en internas partidarias. Ninguno de los dos gobernadores aceptaba la posibilidad de ceder el primer puesto en una posible fórmula presidencial que los 
incluya a ambos, y frente a esta situación, cafieristas y menemistas se volcaron de lleno a pautar la forma y fecha de las internas. Durante estas negociaciones, Menem supo blandir un argumento fuerte para obtener condiciones beneficiosas: si no se elegía sólo la fórmula presidencial en elecciones abiertas y tomando al país como distrito único, rompería con el partido y se presentaría por fuera del peronismo. Cafiero, en pleno ascenso político y en control del propio partido, consideró irrelevantes estas cuestiones y cedió ante la presión del riojano.

La primera dupla en hacerse pública fue la conformada por Menem-Duhalde, dada a conocer el 5 de mayo de 1988. Electo diputado por la provincia de Buenos Aires pocos meses antes, Eduardo Duhalde se había convertido en una de las figuras fuertes del peronismo en el sur del conurbano bonaerense gracias a la gestión como intendente de Lomas de Zamora durante los cuatro años anteriores. En ese entonces había sido uno de los primeros aliados importantes de Cafiero en la provincia, pero esta relación se dañaría de modo irreparable durante las elecciones de septiembre 1987, cuando el líder de la Renovación le negó primero la candidatura a vicegobernador y luego el primer lugar en la lista de diputados. Duhalde, al ver como esos cargos eran ocupados por figuras que poco habían contribuido a la Renovación -Luis María Macaya acompañó en la formula a Cafiero e Ítalo Luder encabezó la lista de diputados-, decidió unirse a las filas del menemismo, aportando una fuerza clave en la provincia de Buenos Aires. La decisión de Menem de elegirlo como compañero de fórmula respondió, entre otras cuestiones, a los votos que podía recuperar en uno de los distritos más poblados del país y a la imagen de político renovador que poseía Duhalde. Esto último le servía a Menem para contrarrestar las acusaciones que recibía del cafierismo sobre la integración a su estructura bonaerense de figuras ligadas al herminismo.

Tres días después de que se conociera el candidato a Vicepresidente de Menem, Cafiero dio a conocer el suyo. Los aspirantes que se barajaban en los días previos al anuncio eran J osé María Vernet y J osé Manuel De la Sota. Carlos Grosso, otro posible candidato, había quedado descartado ya que su imagen era fuerte en Capital Federal, y se buscaba contrapesar la figura de Cafiero con un representante del interior. Vernet, además de ser un político con amplia representación en su Santa Fe natal, simbolizaba la reconciliación con buena parte de la ortodoxia, que estaría aceptando incorporarse al proyecto renovador. Lorenzo Miguel había hecho público su respaldo a esta posible fórmula destacando la importancia de respetar el lugar de cada sector dentro del partido. Pero el círculo de renovadores más cercanos a Cafiero, conocidos como la banda, se opuso diametralmente a Vernet, buscando mantener lo más lejos posible a Miguel y sus hombres. Integrada por Grosso, De la Sota, Manzano y 
García, la banda representaba la cara opuesta al miguelismo: sus dirigentes eran jóvenes de discurso progresista, que prácticamente no habían participado en el peronismo previo al '83. Su idea de Renovación del partido implicaba una Renovación de métodos, de discursos, pero sobre todo, de hombres. Como destaca Gabriela Cerruti, para ellos no se trababa de renovar el justicialismo, sino de refundarlo (CERRUTI, 1993, p. 231). Cafiero, que durante su larga trayectoria en el peronismo había sido compañero de muchos de sus actuales rivales, valorizaba una unidad gobernada por la Renovación, aunque también era consciente de los problemas que esa solución le traería con sus colaboradores más cercanos. La presión de la banda terminó dando sus frutos, y Cafiero eligió a De la Sota como su acompañante. El cordobés le dio un perfil más homogéneo y coherente a la fórmula presidencial pero al elevado costo de perder el apoyo del sindicalismo uominista. El mismo día en que se anunciaba la fórmula, Miguel criticó al propio Cafiero por haber elegido a un candidato que, además de haber perdido en su propia provincia, rompía el equilibrio interno en el peronismo al establecer una fórmula completamente renovadora (Clarín, 9/3/1988). La respuesta de De la Sota no se hizo esperar, marcando que el Secretario General de la UOM podía mostrar su disconformidad "sin que nadie le tape la boca con el bombo" y "sin que nadie lo sancione por pensar diferente" gracias a la existencia de los renovadores (Clarín, 14/3/1988). Tres días después la UOM recogió el guante y, vía solicitada en los diarios, acusó a De la Sota de olvidar la gestión que, bajo su consentimiento, las 62 Organizaciones realizaron para que él fuera incluido como Diputado Nacional (Clarín, 17/3/ 1988).

La apuesta de Cafiero al elegír un vicepresidente del riñón de la Renovación apuntaba al enfrentamiento con la fórmula del oficialismo, cuyos integrantes, Eduardo Angeloz y Juan Manuel Casella, ya eran de público conocimiento. En ese hipotético escenario, la dupla renovadora tendría asegurado el apoyo del peronismo y estaría en mejores condiciones de atraer al electorado independiente que una pareja con presencia ortodoxa. Sin embargo, esta decisión podría traer problemas en la interna partidaria, como ya vislumbraban los analistas políticos en aquel entonces. ${ }^{4}$ En efecto, la designación de De la Sota y sus entredichos con Miguel le quitaron no sólo el apoyo de las 62 organizaciones, sino también el de gobernadores o dirigentes importantes, que, con otro representante en la fórmula, se hubieran volcado hacia Cafiero. Tales eran los casos, entre otros, del gobernador de Mendoza, Octavio Bordón, que pasó de ser un

4 Dos días después de la oficialización de la precandidatura Cafiero-De la sota, el periodista Ricardo Kirschbaum destaca el riesgo de perder la elección interna que corría la pareja renovadora al disipar el apoyo que las 62 Organizaciones ya habían garantizado a la posible fórmula CafieroVernet. Ver Clarín 10/3/ 1988. 
renovador más a declararse prescindente; de J orge Busti, gobernador de Entre Ríos, que recién a último momento se mostró favorable a Cafiero; y del vicegobernador de Santa Fe, Antonio Vanrrell que al mostrar su apoyo a Menem contrapesó las modestas gestiones de Vernet a favor del renovador en la provincia. Inclusive en el Gran Buenos Aires, uno de los bastiones a priori más importantes del cafierismo, comenzaron a surgir intendentes menemistas, como fueron los casos de Alberto Pierri en la Matanza, Hugo Villaverde en Almirante Brown, Luis Colabianco en Magdalena, y Carlos Castro en Coronel Brandsen. Las gestiones de Duhalde fueron fundamentales para revertir la firme mayoría de Cafiero en esta zona, pero también fue importante el discurso que sostuvo Menem, dirigido directamente a las clases más bajas. En este discurso, los culpables de la pobreza eran los impulsores de la politiquería liberal, que incluía tanto al oficialismo como a los renovadores.

Cafiero, por su parte, facilitó esta asimilación con el alfonsinismo al convertirse, desde la gobernación bonaerense, “[...] en el impulsor de la colaboración con el oficialismo [...]" (NOVARO, 2006, p. 201) durante los primeros meses de 1988. Los acuerdos establecidos entre el oficialismo y el cafierismo giraron en torno a temas económicos, y más precisamente, a medidas muy poco populares como lo eran el aumento de impuestos a los sectores medios y el recorte de fondos nacionales para la provincia de Buenos Aires. Como destaca J oaquín Morales Solá, Cafiero cristalizó una imagen de aliado de Alfonsín precisamente en sus aspectos menos simpáticos, en el marco de un proceso electoral interno en el que sólo votaban peronistas (MORALES SOLÁ, 1991, p. 86). Para peor, las medidas económicas del gobierno nacional no arrojaban resultados positivos, sino todo lo contrario. La Renovación cafierista había decidido cerrarse apostando a disputarle el espacio propio al alfonsinismo en un momento de crisis de ese mismo terreno.

Las elecciones internas del 8 de julio de 1988 dieron como triunfadora a la fórmula Menem-Duhalde, con el 52\% de los votos. Altamirano resume de forma muy ilustrativa las causas del triunfo menemista cuando señala que "el proyecto ordenado en torno de definiciones ideológico-políticas atraía más a los militantes y a los sectores medios que a los sectores populares; que éstos se reconocían más en el discurso milagrero del Menem de entonces, que asumió la figura de quien no pertenecía al sistema político y llegaba para luchar en nombre de un peronismo plebeyo contra un peronismo de saco y corbata, 'alfonsinisado' o socialdemócrata; en fin, que los cuadros políticos jóvenes que acompañaban a Cafiero irritaban a los dirigentes sindicales de los gremios fuertes, y que el apoyo que los renovadores recibían del grupo de los 25, en su 
papel de rama sindical de la corriente, no compensaba la hostilidad de las 62 Organizaciones" (ALTAMIRANO, 2004, p. 73).

Esos escasos cuatro puntos porcentuales que separaban a los dos candidatos pusieron fin a la Renovación. Los integrantes de la banda, temiendo quedar expuestos al vacío en que caía su líder, procuraron pasarse al menemismo lo antes posible. Grosso aspiraba a ser intendente de Buenos Aires en 1989, y para lograrlo necesitaba el consentimiento de Menem ya que se trataba de un cargo designado por el presidente. J osé Luis Manzano, por su parte, pudo acercarse con facilidad al riojano gracias a los contactos que mantenía en la Cámara Baja con diputados menemistas, especialmente Eduardo Bauzá y J ulio Corzo. Esta primera desarticulación de la Renovación obligó al resto de sus miembros a seguir el mismo camino, poniendo fin al proyecto que había logrado oxigenar al peronismo durante los años de Alfonsín, y que ahora se hundía junto con el líder radical. La crisis del alfonsinismo, que era percibida como necesaria para el éxito renovador, terminará siendo también un elemento que arrastre a la Renovación al mismo fracaso que sufría el radicalismo entre 1988 y 1989.

\section{Comentarios Finales Sobre la Renovación}

Definir o caracterizar a la Renovación Peronista con cierto grado de precisión resulta una tarea compleja. Marcos Novaro, consciente de esta dificultad, sostiene que la Renovación era una "heterogénea coalición de líderes que tenía dos elementos en común, el ser mejor vistos por el electorado que los ortodoxos y los sindicalistas, y el aspirar a crear un partido basado ya no en los gremios sino en estructuras territoriales" (NOVARO, 2006, p. 200). Novaro, inclusive, complejiza su propia caracterización, al destacar que el proceso de partidización territorial del PJ comenzó, paradójicamente, con Herminio Iglesias, responsable de la creación de la red de Unidades Básicas en la Provincia de Buenos Aires, sobre la cual luego se montarían los renovadores.

El término comenzó a utilizarse durante el primer año del gobierno radical para nombrar a quienes se oponían a la conducción peronista, culpable de la derrota del '83. Esta gran primera Renovación, que logró juntar a los más de 400 congresales necesarios para nombrar una nueva conducción partidaria, incluía, sin embargo, a figuras que rápidamente arreglarían sus diferencias con los ortodoxos y se sumarían a su ala, como fue el caso del gobernador de Catamarca, Vicente Saadi. Sólo un pequeño grupo de estos primeros renovadores continuará enfrentado a la ortodoxia, buscando organizarse en torno a la conducción tripartita de Cafiero, Grosso y Menem.

La figura de Menem ilustra algunos de los problemas que presenta la delimitación de la Renovación Peronista. Constituyó una pieza clave en los primeros 
años de la Renovación, no sólo por su oposición a la ortodoxia siendo un gobernador provincial, sino también por su discurso aggiornado al nuevo tiempo democrático y por sus actitudes de conciliación respecto al alfonsinismo, en franca disidencia con la dirigencia justicialista. Si esto lo convertía en un renovador paradigmático, el cambio que experimentó su perfil a medida que aumentaba su enfrentamiento con Cafiero lo reconvirtieron en un anti-renovador. No sólo comenzó a acercarse a los dirigentes ortodoxos, con quienes estableció fuertes alianzas, sino que también modificó el tono de su discurso volviéndolo más ecléctico, apelando a la liberación nacional, al salariazo, a la virgen María y a la pena de muerte para narcotraficantes, entre otros. Decidió distanciarse tanto del presidente de la nación como de su contrincante en las internas. Hasta tal punto Menem efectivizó su transformación que en las internas de 1988 el adjetivo renovador sólo hacía referencia al cafierismo. "A la Argentina no hay que renovarla, hay que liberarla" repetía el gobernador de la Rioja en aquel entonces, consciente de su propio alejamiento del espacio y del discurso renovador.

Este cambio abrupto en el perfil político del propio Menem, nos permite pensar que mientras participó de la causa renovadora, su interés radicaba más en obtener un provecho político a partir de un discurso aceptado socialmente que en emprender una verdadera transformación del peronismo acorde a los ideales democráticos en boga. Distinta pareciera ser la situación tanto de Cafiero como de la banda, aunque aquí cabe marcar otro tipo de divergencia referido al sentido que la Renovación tenía en uno u otro sujeto. Como mencionamos antes, Cafiero, que había mantenido estrechas relaciones con el vandorismo en los '60, y que había sido asesor de la CGT durante buena parte de los '60 y comienzos de los '70, buscaba modificar esencialmente la forma en la cual se nominaban los candidatos dentro del partido. Poner fin a las digitaciones tras bambalinas comandadas por dirigentes poco representativos para instaurar un partido transparente y democrático, donde los representantes sean fiel expresión de las bases. Para la banda, la Renovación iba más allá de la instauración de reglas compartidas, e implicaba un necesario recambio dirigencial. Acercar posiciones con los ortodoxos representaba para ellos claudicar en su proyecto renovador. Este nuevo peronismo podía y debía prescindir de dirigentes cuyo discurso y práctica no se adecuaba a la propuesta renovadora y cualquier vínculo con ellos era considerado un perjuicio más que un provecho. Si bien podríamos decir que los miembros de la banda representaban el peronismo más fuertemente renovador, también es verdad que fueron los primeros en abandonar este espacio y pasarse al menemismo cuanto Cafiero perdió las internas. Toda su apuesta por la Renovación fue desarticulada en muy poco tiempo, 
y saltaron sin demasiadas vacilaciones a engrosar un proyecto que compartía pocos puntos en común con la Renovación que antes habían defendido con extremo purismo.

\section{Referecias}

ABOY CARLÉS, Gerardo. Parque norte o la doble ruptura alfonsinista. In: NOVARO, Marcos; PALERMO; Vicente (Comp.). La historia reciente: Argentina en democracia. Buenos Aires: Edhesa, 2004.

ALTAMIRANO, Carlos. La lucha por la idea: el proyecto de la renovación peronista. In: NOVARO, Marcos; PALERMO; Vicente (Comp.). La historia reciente: Argentina en democracia. Buenos Aires: Edhesa, 2004.

CERRUTI, Gabriela. El J efe, Vida y obra de Carlos Menem. Buenos Aires: Planeta, 1993.

DE IPOLA, Emilio. Veinte años después (Parque Norte: razones del fracaso de un intento inédito de enfrentar la crisis en la Argentina). In: NOVARO, Marcos; PALERMO; Vicente (Comp.). La historia reciente: Argentina en democracia. Buenos Aires: Edhesa, 2004.

GUIDO, Ricardo; DOMENICONI, Hector. Las primeras elecciones sindicales en la transición democrática. Desarrollo Económico, v. 26, n. 103, 1983.

IVANCICH, Norberto. La larga marcha: de la institucionalización del PJ , hasta la instauración del menemismo. [200-]. Disponible en:<www.croquetadigital.com.ar>. Aceso en: nov. 2010.

MORALES SOLÁ, J oaquín. Asalto a la ilusión, Historia secreta del poder en la Argentina desde 1983. Buenos Aires: Planeta, 1991.

NOVARO, Marcos. Historia de la Argentina contemporánea. De Perón a Kirchner, Buenos Aires: Edhesa, 2006.

ROMERO, Luis Alberto. Breve historia contemporánea de la Argentina. Buenos Aires: Fondo de Cultura Económica, 2001.

VOMARO, Gabriel. Cuando el pasado es superado por el presente: las elecciones presidenciales de 1983 y la construcción de un nuevo tiempo político en la Argentina. In: PUCCIARELLI, Alfredo (Coord.). Los años de Alfonsín. Buenos Aires: Siglo XXI, 2006. 
Antonio Otaviano Vieira J unior

La renovación peronista en cuestión: una aproximación a la experiencia del peronismo.. 